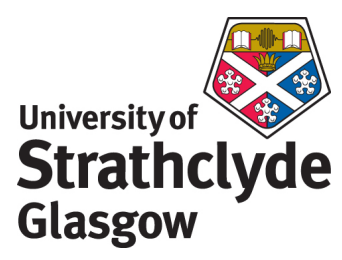

Grierson, D. and Hyland, Claire (2010) Towards a framework for university-wide postgraduate programmes in sustainability. International Journal of Interdisciplinary Social Sciences . ISSN ISSN: 1833-1882

http://strathprints.strath.ac.uk/28495/

Strathprints is designed to allow users to access the research output of the University of Strathclyde. Copyright $(C$ and Moral Rights for the papers on this site are retained by the individual authors and/or other copyright owners. You may not engage in further distribution of the material for any profitmaking activities or any commercial gain. You may freely distribute both the url (http://strathprints.strath.ac.uk) and the content of this paper for research or study, educational, or not-for-profit purposes without prior permission or charge. You may freely distribute the url (http://strathprints.strath.ac.uk) of the Strathprints website.

Any correspondence concerning this service should be sent to The Strathprints Administrator: eprints@cis.strath.ac.uk 


\title{
Towards a Framework for University-wide Postgraduate Programmes in Sustainability
}

\author{
David Grierson, University of Strathclyde, Scotland, UK \\ Claire Hyland, University of Strathclyde, Scotland, UK
}

\begin{abstract}
The role of Higher Education Institutions in addressing social, environmental, and economic challenges and opportunities in today's world is immense, complex, and vital (GUNI, 2008). Traditionally responses to sustainable development (SD) have been concentrated within specific subjects, however there has been a gradual penetration of sustainability issues into a wide spectrum of disciplines (HEA, February 2009. The definition and priorities of SD are complex and multi-layered and the challenges presented, being inherently holistic, require equal responses from all disciplines. This requires the development of a framework for University-wide, cross disciplinary teaching. The University of Strathclyde has been ranked first in the Engineering Education for Sustainable Development (ESD) Observatory Report 2008. Building on this success, work is underway to develop a university-wide, interdisciplinary Strathclyde Masters programme in Sustainability (SMS, aimed at articulating a framework for integrating flagship postgraduate courses \& classes, sustainability literacy \& skills training workshops. This paper summarises the theories of sustainability and its inherent interdisciplinary nature by examining current thinking in ESD. This has highlighted the need to review the current curriculum, identifying current interdisciplinary provision aligned with ESD, and implement a multistakeholder consultation process. The paper describes how these theories might be put into practice, detailing the conclusions drawn from the initial consultation process involving external organisations, students, academic staff and the university's professional services. In addition, a model 'Sustainability Map' is presented offering an overview of postgraduate provision of ESD within the institution as a whole, alongside details of the courses offered and contributing departments. The outcome of the multistakeholder consultation process, in conjunction with the 'Sustainability Map', will help inform future consultation focusing on structural refinement and the academic content of the interdisciplinary programme.
\end{abstract}

Keywords: Interdisciplinarity, Postgraduate Programmes, Education for Sustainable Development, Stakeholder Consulation

\section{Introduction}

$\mathrm{I}$

T IS INTENDED that this paper add to the current literature and case studies detailing good practice lessons in embedding and promoting education for sustainable development within Higher Education Institutions (HEI's). At the mid-point of the United Nations Decade of Education for Sustainable Development (UNDESD) it is crucial that educators, particularly HEI's, who are more autonomous in their policy making than pre-16 education, share their experiences and good practice methods of incorporating Education for Sustainable Development (ESD) within the curriculum. To this end, the paper describes research that has taken place at the University of Strathclyde since January 2009. It aims at the development of a framework for university-wide, cross disciplinary research and postgraduate teaching

The International Journal of Interdisciplinary Social Sciences

Volume 5, Number 2, 2010, http://www.SocialSciences-Journal.com, ISSN 1833-1882 
in the area ESD. The vision for the Strathclyde Masters programme in Sustainability (SMS) provides context for the three main stages of the research which have been undertaken, being: (i) a review of current thinking in ESD, (ii) a structured consultation programme and (iii) the creation of both a current and future 'sustainability map' showing postgraduate provision of ESD within the University. A brief summary of the definitions of sustainable development (SD) is offered before an exploration of the concept of ESD and its inherent disciplinary nature. The paper then examines the role that universities play in addressing the challenges of SD and describes the achievements that have established the University of Strathclyde as an emerging leader in the field of ESD. The review of current thinking in ESD uses literature and case studies detailing initiatives to embed ESD within Higher Education Institutions, to draw on recurring themes, graduate attributes and associated pedagogies. The paper then details the conclusions drawn from the initial multi-stakeholder consultation process involving external stakeholders, students, academic staff and the university's professional services. In addition, the model 'Sustainability Map' is presented offering an overview of postgraduate provision of ESD within the institution as a whole, alongside sample details of the courses offered and contributing departments.

\section{SMS Vision}

The University of Strathclyde aims to promote and undertake a visionary programme of cross-disciplinary research and postgraduate teaching in sustainable development, relevant for Strathclyde Graduates and Degrees for the 21st Century and in support of the 'One Strathclyde' approach. The Vision of the University as an international technological university and the Strategic Plan for the University (2011-2014) provide the context for the development of this proposed multi-Faculty initiative, which will build on the existing highquality provision of ESD within the University. The SMS project aims to articulate a framework for integrating flagship postgraduate courses \& classes, sustainability literacy \& skills training workshops, and subsequently Continuing Professional Development (CPD) courses. The new pan-university SMS programme will champion critical thinking in sustainability while promoting interdisciplinary working in collaboration with business and industry. Increased internationalisation and an enhanced student learning experience are main objectives for the programme. Central to this is the development of networks and mechanisms for effective knowledge exchange, innovation and engagement with stakeholders. The aim of the first stage of the proposal is to define a clear structure for the integration of postgraduate provision within the sustainability area involving input from relevant stakeholders, and provide an integrated framework for University-wide educational activities in the sustainability area that will enhance the learning experience of students.

\section{Sustainable Development}

'Sustainable development' and 'sustainability' have been given many and varied definitions and this has been described as necessary in order that these concepts can be applicable locally and globally in different situations and cultures. Our Common Future (the 1987 Report of the UN World Commission on Environment and Development - generally referred to as the Brundtland Report) offers the most widely used definition of sustainable development: 
"Humanity has the ability to make development sustainable - to ensure that it meets the needs of the present without compromising the ability of future generations to meet their own needs."

(UNWCED, 1987)

Sustainable development involves a process of moving society's currently unsustainable activities towards a pattern that can be sustained into the future. While there has been a lot of attention paid to environmental impact on the planet, less attention has been paid to sustainable social and economic issues. It is widely accepted that the environment, economy and society are the three pillars of sustainability and that equal importance should be given to each.

\section{Education for Sustainable Development}

Since sustainable development was first endorsed at the UN General Assembly in 1987 the concept of education and learning to support sustainable development has been explored and promoted. The period $2005-2014$ has been declared as the United Nation Decade of Education for Sustainable Development (UNDESD, Johannesburg Summit, 2002). The goal of DESD is to integrate the principles, values, and practices of sustainable development into all aspects of education and learning. The need for ESD has now been recognised by many national and international education and government bodies (UNESCO, Nov 2008). In countries where environmental education is already a formal part of the curriculum it has been found that ESD tends to build upon structures and policies already in place (UNESCO 2009). The issues relating to sustainable development are complex and multi-layered necessitating interdisciplinary solutions and thinking. Therefore, it is necessary to approach ESD in a holistic fashion and not solely through any single-discipline, viewing it as an integrative, cross-curricular theme which can bring together many subject areas.

\section{Universities and Sustainable Development}

The United Nations advocate that higher education will be key to changing and reshaping society's attitude towards achieving a sustainable future. As centres of knowledge production and exchange, and training provision, universities are well positioned to connect the local (through close links with neighbouring communities, business, and industry) and the global (through associations with international learning and research networks). In this way universities have considerable access to, and influence over, human development processes. "Human development is about...creating an environment in which people can develop their full potential and lead productive, creative lives in accord with their needs and interests" (UNDP, 2007). A number of well known global frameworks and initiatives support these values including The Millennium Development Goals, the UN Kyoto Protocol, and the UNESCO Decade of Education for Sustainable Development (2005 - 14). However these frameworks, of themselves, do not provide a guarantee of positive change. Progress towards some of the targets enshrined within them has been slow or nonexistent. The challenges involved are massive and cannot be underestimated. Huge disparities between the developed and developing nations are at the heart of this. 
UNESCO (2005) contends that education will play a vital role in sharing, applying and creating knowledge in a globalizing world. Universities will fuel the driving forces of transformation towards a global knowledge society. They have the capacity to steer and eventually correct the direction of (negative - unsustainable) trends within globalisation. The process of sustainable development requires that we all attain the skills needed to handle the complex challenges of change and uncertainty, and the ability to communicate with a large number of stakeholders. In this sense universities are working at different levels to become engines of wider societal change - to address both global and local needs and priorities. The contribution of universities to the sustainability agenda is being expressed in transdisciplinary research and knowledge exchange activity and more recently embedded within teaching and learning provision. Universities have a dual responsibility - to provide graduates with the attitude, knowledge and skills to lead this process, while also developing the knowledge to support research on Sustainable Development (SD) \& share knowledge with external partners. In responding to this challenge, universities are developing not only their capability to articulate a vision of a better world (and solutions to today's problems) but also their willingness and ability to reach out towards an unknown future by working in partnership with many others, both locally and globally.

\section{The University of Strathclyde}

The University of Strathclyde has national and international leading research opportunities in a number of sustainability-related areas and has been at the forefront of environmental education, and interdisciplinary teaching in sustainability-related areas since the 1990s. As a result of these activities and planned initiatives such as the SMS the University has recently been recognised as a leading European institution in addressing issues of sustainable development. Strathclyde has been ranked first of 56 technological universities in the recent European sustainability rankings by the Engineering Education for Sustainable Development Observatory Report 2008 (EESD, 2008). The report identifies the extent that sustainability is embedded in research, undergraduate and postgraduate education within the curricula, and within approaches to institutional management. The University of Strathclyde is the only university thus far to have achieved a score above 9 placing the university in the 'inspiration' category. A major contributor to this achievement was the Sustainable Engineering programme, launched in 1999, which integrates MSc courses from across the various engineering disciplines. Graduates gain advanced technical and 'soft skills' training to meet Engineering Council requirements to support chartered engineer status. A major benefit is the opportunity for students to complete a group project for an industrial client with input from different disciplines. This provides a vehicle for industrial involvement and knowledge exchange, with findings disseminated at an annual conference. There is widespread use of online learning in the classes where groups of students from different disciplines and cultures have the chance to debate and discuss issues related to the learning resources provided in the class. Over 500 students have graduated from the SE programme with a variety of attributes, including skills dealing with issues of complexity, enhanced communication and networking. Along with knowledge of sustainability, students foster a social and political agency and group work gives them an appreciation of the role of others within an interdisciplinary working environment (CSF, 2009). This innovative approach to the sustainable development agenda ensures students receive advanced engineering training, and gain invaluable insights 
into how to address some of the issues that companies face when integrating sustainable practices into their businesses.

\section{Current thinking in ESD}

A review of current thinking in ESD draws on common aspects of various case studies relating to initiatives aimed at embedding ESD within the curriculum. The Higher Education Academy emphasises that a rigorous process of consultation offers a vital tool in module, course, and programme review and in supporting curriculum renewal and development (HEA, Apr 2008). ESD may be interpreted in a variety of ways according to regional, national and local differences and it is therefore imperative to involve a wide range of stakeholders in the development and implementation of any ESD related framework (UNESCO 2009). An important first step in developing the SMS was to establish multi-stakeholder consultation groups which included all postgraduate students within the university; SMS Faculty representatives nominated by the Deans to represent each Faculty; university management and professional services, as well as external stakeholder organisations nominated to represent each faculty and led by a smaller SMS External Working Group. Various methods of engagement were explored and careful consideration given to the initial multi-stakeholder consultation process. Identified objectives were to define: discipline related demands of sustainable development and generic skills required to deal with these demands; the best approach to embed ESD within university-wide integrated provision; requirements for curriculum renewal for ESD; appropriate flexible teaching delivery methods; key attributes for new graduates, and stakeholder willingness to embed ESD.

It was also highlighted that an important preliminary step in establishing an appropriate approach to embed ESD within an institution is to analyse provision within the existing curriculum through a process of review and consultation. It is imperative to establish which areas work well and already incorporate ESD, or can be easily adapted to incorporate ESD within a structured process of curriculum renewal. Currently there exists significant variation in practice across many subject areas (HEA, January 2006), however many of the objectives and pedagogies of ESD are similar irrespective of subject area. Provision of ESD is in many cases already part of the formal education curriculum, but not identified as such (UNESCO 2005). The Higher Education Academy's Review of Education for Sustainable Development in Scotland (HEA, February 2009) found that there has been a gradual penetration of sustainability issues into a wide spectrum of disciplines taking shape in formal 'flagship' courses, and a gradual embedding of these issues into the curriculum. ESD has filtered through disciplines such as environmental sciences and architecture, where a specific concern for a more efficient use of natural resources has had an impact on professional regulations and accreditation requirements, and is now emerging in many other subject areas. In order to identify appropriate teaching methods it is important to establish the relevant discipline-related concepts in sustainability and evaluate current course provision (UNESCO 2009). As such, all Departments within the University have been asked to contribute to the creation of a "Sustainability Map" which details postgraduate provision of ESD within the university.

The need for increased provision of interdisciplinary teaching and research opportunities was reinforced throughout case studies. In order to deal with issues of sustainability it is necessary to be equipped not only with a strong technical knowledge and the ability to work in a team, but also the necessary vocational and social skills, and new learning processes 
and educational methodologies should be developed in order to achieve this (UNESCO 2009). Identifying and setting thematic priorities in the curriculum, while at the same time emphasising a holistic approach, can be complex. Case studies have suggested that a shift is needed from more traditional teaching delivery methods to problem-based learning. The UNESCO Review of Contexts and Structures for Education for Sustainable Development 2009 (UNESCO 2009) has acknowledged increased networking at a local, national and international level to be crucial. Furthermore it has called for multi-stakeholder dialogue between individuals and organisations representative of all dimensions of ESD to be strengthened during the remaining half of the DESD. As indicated in the

Higher Education Academy's report, Sustainable Development in Higher Education, Current Practice and Future Developments (HEA, Jan 2006), most subject centres found that this engagement could be achieved either through real-world, project-based work, field work, site visits, case studies and / or by asking students to apply their discussion of literary texts to other areas of their lives. Examples included the use of a Virtual Learning Environment (VLE) as a flexible teaching tool, and the direct involvement of industry through engagement in providing and helping with supervision of 'live' projects. The direct input of industrial and practice-based representatives within learning modules also supported wider engagement. Relationships between teachers, researchers, and industry \& government can have benefits for all parties, and help support research / teaching linkages. The consultation process has explored the required graduate skills and attributes necessary in order to deal with the demands of sustainable development as well as favoured approaches to helping students develop these skills and how these can be embedded within the curriculum. It is envisaged that through multi-stakeholder involvement in these key areas, opportunities for multidisciplinary real live project-based learning and research, and knowledge exchange activity will be enhanced and strongly supported both externally and within the University itself.

\section{Multi-stakeholder Consultation}

To date initial consultation has been held with three main groups; academic staff and the university's professional services, postgraduate students, and external stakeholders led by the SMS Working Group. Faculties have been represented by SMS Faculty Representatives nominated by the Dean of each faculty. These representatives were asked to nominate external stakeholders to be contacted, with input from the External Working Group who were responsible for leading external consultation. The Delphi consultation method was used to consult with external stakeholders and students. This involved sending out initial open-ended questionnaires to small target groups, which were analysed and the answers then sent out to be rated by the same respondents and an extended larger group. While most questions were of a quantitative nature asking participants to rate options given, a commentary box was provided after each question to allow a more in-depth analysis of certain answers. Information extrapolated from these questionnaires was used to inform a Postgraduate Student Focus Group meeting held in September 2009 following an External Focus Group meeting held in August 2009. Various consultation methods were used in order to engage academic staff and the University's Professional Services. SMS Faculty Representatives were consulted through a number of meetings and assisted in disseminating relevant information through the faculties. These representatives were also present at the SMS External Focus Group 
meeting, alongside a representative from Careers Service and the Secretary to the University. Additionally, all Heads of Department were sent an abbreviated review of current thinking in ESD and asked to contribute to the Sustainability Map. Summary reports of each focus group meeting were sent to all attendees and SMS Faculty Representatives and their feedback welcomed. A final report detailing the entire process was also sent to those involved in the consultation process. In the following sections further analysis undertaken in Spring 2010 is presented, drawing on significant results from both the postgraduate student and external stakeholder surveys.

\section{Student Consultation}

A total of 204 postgraduate student responses were collected, with an almost even gender division between female (57\%) and male (43\%). Participants came from a variety of different backgrounds producing a varied first-degree profile. A total of 39 different nationalities were represented highlighting the large international community that already exists at the university (see Figure 1).

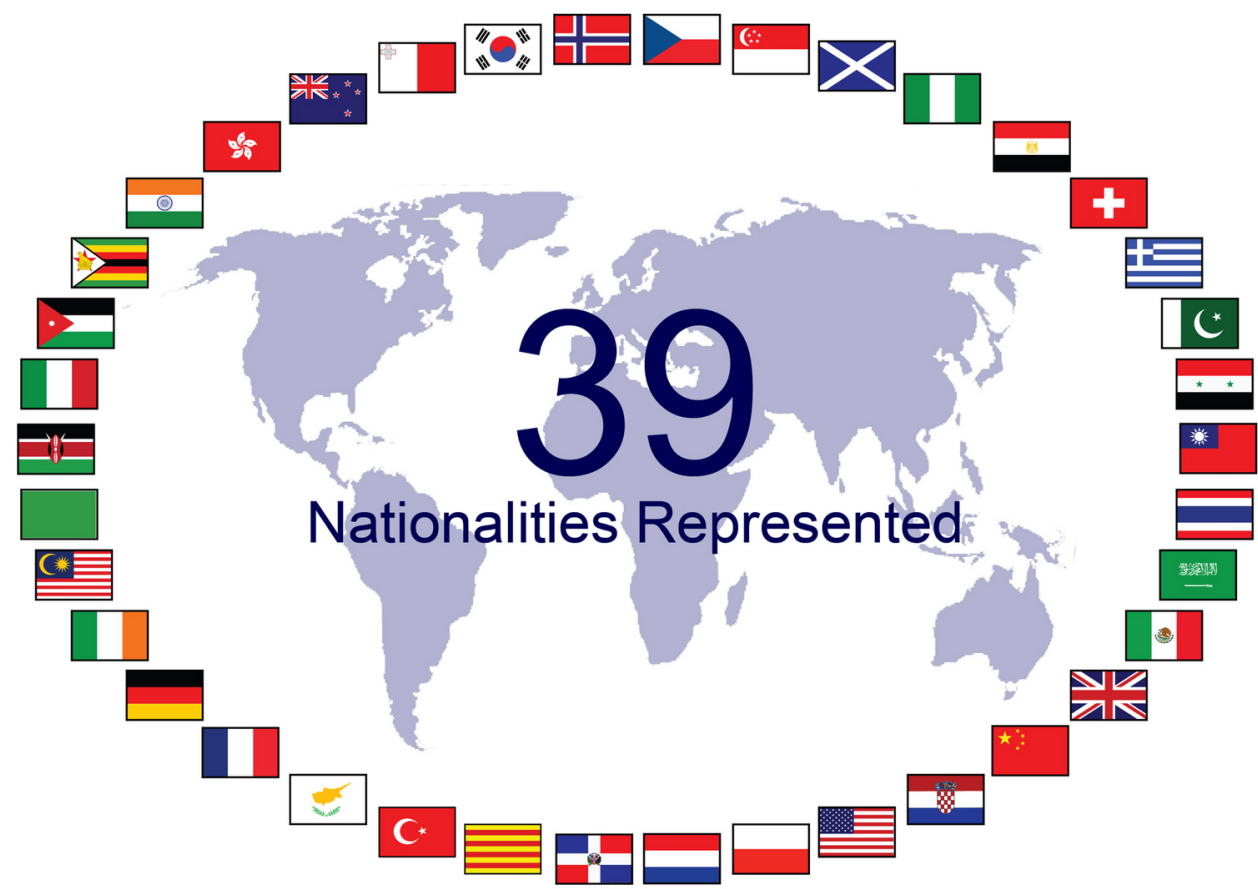

Figure 1: Flags of the 39 Nationalities Represented in the Postgraduate Student Survey

The most popular reason for selecting a particular course or field of study was the chance of enhancing employability (54\%) which reinforces the need for close consultation with external stakeholders when identifying necessary graduate attributes. Approximately half of respondents $(53 \%)$ stated that their research topic or course choice did not relate directly to sustainability issues and almost the same amount (48\%) felt that not enough emphasis was placed on sustainability issues in their particular field of research / course choice. Signi- 
ficantly, $46 \%$ of respondents said that their current course did not give them the opportunity to mix with students from other disciplines and to learn inter-disciplinary skills, and a large majority $(85 \%)$ felt that the chance to interact with other disciplines would be beneficial to their studies. Students were asked to rate (in order of importance) the skills they believed were necessary in dealing with the main challenges posed by sustainable development in the context of their field of research (see Table 1). Interestingly, the results concurred with those from the external stakeholder group in their selection of the 'ability to prioritise tasks and manage time', closely followed by 'knowledge of sustainability'. However they differed in their ratings of 'knowledge of recent advances within your field'. Communication and networking skills were seen to be just as important as technical knowledge, which concurred with important skills identified in relevant case studies.

Table 1: Skills Needed to Deal with the Demands of SD in Order of Importance (Rating Scale 1 to 12)

\begin{tabular}{c|l|c}
\hline Rank & \multicolumn{1}{|c|}{ Skills in order of importance } & $\begin{array}{c}\text { Average } \\
\text { Rating score }\end{array}$ \\
\hline 1 & Knowledge of recent advances within your field & 4.44 \\
2 & Ability to prioritise tasks and manage time & 8.19 \\
3 & Knowledge of sustainability & 8.66 \\
4 & Ability to innovate \& be creative & 9.16 \\
5 & Communication \& networking skills & 9.76 \\
6 & Technical knowledge & 9.95 \\
7 & Lateral thinking \& complex problem solving ability & 10.64 \\
8 & Ability to recognise \& validate problems & 11.33 \\
9 & Construct coherent arguments \& articulate ideas clearly & 11.66 \\
\hline
\end{tabular}

When asked how these skills could be incorporated into the curriculum there was a clear emphasis on 'skills training workshops aligned with sustainability' and 'live projects in collaboration with industry' as detailed in Figure 2. 


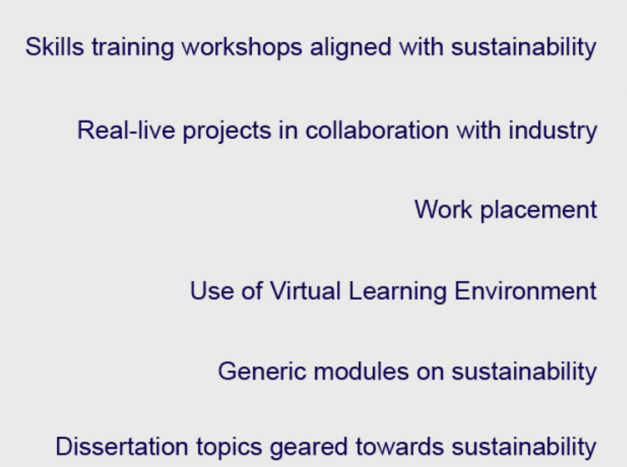

Dissertation topics geared towards sustainability

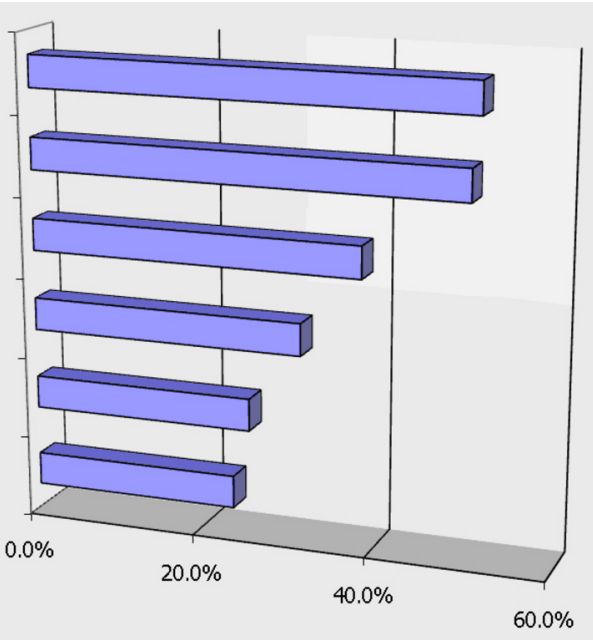

Figure 2: Graph Showing Curriculum Preferences in Order to Instil SD Skills

The large majority (86\%) of students said they would consider a future employer's social and environmental responsibility while seeking employment and a smaller amount (64\%) would consider their chances of employability enhanced by having studied issues relating to sustainability. Commentary following this question indicated that a certain amount of scepticism may exist among students about the importance that employers place on sustainability.

\section{External Consultation}

The external stakeholders contacted included government bodies, independent organisations, industry representatives and local authorities. A total of 23 organisations completed the survey and 18 indicated that they would like to have further input into developing the SMS programme. When asked the demands that sustainable development currently places in context of their particular field of work a large and varied range of responses was received indicating that this could vary depending on a particular field of work and would require more detailed consideration when consulting with individual faculties and representative external stakeholders about specific course content. The highest rated skills in order to deal with the demands of SD (Table 2) were an ability to prioritise tasks and manage time, followed by an ability to make strategic decisions based on a broad understanding of technical, economic, social, political and environmental considerations. However it should be noted that all skills received high ratings of 1 and 2 , and were therefore seen as important. 
Table 2: Skills Needed in Order to Deal with the Demands of SD (Rating Scale 1 to 5)

\begin{tabular}{|c|c|c|}
\hline Rank & Skills in order of importance & $\begin{array}{c}\text { Average } \\
\text { Rating score }\end{array}$ \\
\hline 1 & Ability to prioritise tasks and manage time & 1.63 \\
\hline 2 & $\begin{array}{l}\text { Ability to make strategic decisions based on a broad } \\
\text { understanding of technical, economic, social, political and } \\
\text { environmental considerations }\end{array}$ & 1.64 \\
\hline 3 & Ability to recognise $\&$ validate problems & 1.69 \\
\hline 4 & Knowledge of sustainability & 1.71 \\
\hline 5 & Communication \& networking skills & 1.75 \\
\hline 6 & Technical knowledge & 1.87 \\
\hline 7 & $\begin{array}{l}\text { Ability to think critically rather than simply achieve an } \\
\text { understanding of the subjects taught }\end{array}$ & 2.00 \\
\hline 8 & $\begin{array}{l}\text { Lateral thinking \& complex problem solving ability } \\
\text { Ability to plan scenarios } \\
\text { Ethics awareness }\end{array}$ & $\begin{array}{l}2.07 \\
2.07 \\
2.07\end{array}$ \\
\hline 9 & Construct coherent arguments \& articulate ideas clearly & 2.13 \\
\hline 10 & Knowledge of recent advances within your field & 2.15 \\
\hline 11 & $\begin{array}{l}\text { Ability to innovate } \& \text { be creative } \\
\text { Risk evaluation }\end{array}$ & $\begin{array}{l}2.20 \\
2.20\end{array}$ \\
\hline
\end{tabular}

The two highest rated educational approaches seen as the most effective in helping students to develop these skills were firstly to provide students with an awareness that sustainability depends on a broad range of factors such as climate change, demographics, consumption trends in industrialised, developing and third world countries, energy generation, distribution and efficiency, and secondly to instil a basic understanding of sustainability in each student (see Figure 3). 
Provide students with an awareness that sustainability depends on a broad range of factors such as climate change, demographics, consumption trends in industrialised, developing and third world countries, energy generation, distribution and efficiency (1.57)

Instil a basic understanding of sustainability in each student (1.80)

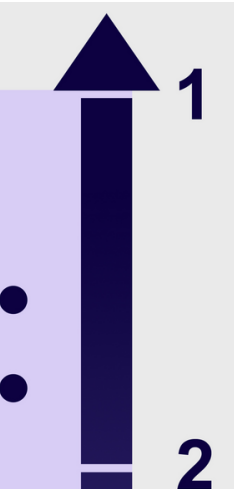

Encourage students to think outside their own speciality or interests (2.14)

Provide students with (generally accepted) statistics on e.g. emissions across various industries, across various contries, energy costs, energy consumption, etc. and encourage them to form their own views rather than accept perceived wisdom (2.53)

Expose students to conflicting but genuinely held opinions $(2.73)$

Figure 3: Educational Approaches to help Students Develop SD Skills (Rating Scale 1 to 5, Average Rating Scores in Brackets)

These findings reinforce the need for a basic understanding of sustainability and an awareness of the complex issues involved when dealing with sustainability, coupled with an ability to make decisions based on this information. Favoured methods of organising such educational approaches within the curriculum focused on core modules on cross-disciplinary topics and live projects in collaboration with industry. Crucially, the vast majority $(93 \%)$ of respondents said that they would consider a graduate's knowledge and skills in sustainable development when recruiting.

\section{Consultation Findings}

Through the multi-stakeholder consultation process it was confirmed that sustainable development (SD) is a priority for both students and employers. It was acknowledged that universities and higher education institutions, as centres of knowledge production \& exchange, have the ability to lead the way in response to the sustainable development (SD) agenda, and that collaboration between universities, government and industry is needed. While the SMS initiative has emerged initially from concerns within architecture and engineering the view was upheld that the challenges of SD require responses from all disciplines and professions represented within the institution.

It was reinforced that an understanding of the complex issues involved in SD and interdisciplinary skills are core requirements. Teaching through skills training workshops and live projects in collaboration with industry are favoured methods of instilling these skills. The idea of introducing generic modules within flagship courses was well received by SMS 
Faculty Representatives and various suggestions offered as to how the structure of the SMS could be developed. Knowledge of sustainability can be instilled through generic modules which allow students of different disciplines to exchange ideas and work at a similar level. Difficulties occur when addressing more specific subject areas as students from different disciplines have varying levels of expertise and both should benefit from the experience. Interdisciplinary group projects allow students to gain practical interdisciplinary skills while at the same time developing technical skills in their specific area of study.

It was acknowledged that collaboration with industry brings benefits to all parties and live projects set by industry should be enhanced through a more structured form of communication between the student, industrial support and academic support. Course accreditation by professional bodies should be taken into account when developing the academic content of the SMS. It was agreed in principle that the Strathclyde Masters programme in Sustainability (SMS) is an initiative that requires university-wide collaboration. It was acknowledged that continued consultation with all stakeholders will be important to the success of the initiative and should ensure benefit for all participants. Existing staff-student liaison structures set up to support undergraduate courses might be adapted for postgraduate level in order to support this continuing consultation process.

\section{Sustainability Map}

SMS Faculty Representatives and Heads of Department were asked to contribute to the creation of a Sustainability Map by detailing any current or future postgraduate courses or modules they felt could be aligned with ESD, and might inform future discussion on the programme content of the SMS. Figure 4(a) shows general postgraduate ESD activity across the University and the Sustainable Engineering Programme running across the departments of the Engineering Faculty. This diagram was constructed using more detailed tables which list postgraduate courses and modules available under contributing departments, an example of which is given in Table 3. As expected there is a stronger presence of ESD within the Faculty of Engineering. This is concurrent with the review of current thinking in ESD, which acknowledged ESD to be stronger in certain disciplines than others. There was also found to be a strong presence of external links with other HEI's and industry, as well as internal collaboration with cross-departmental and cross-faculty courses sharing modules, which should be built upon (CSF, 2009). A future Sustainability Map is presented in Figure 4(b) showing a more even distribution across all subject disciplines and individual Sustainability 'packages' to be provided by each Faculty. It is envisaged that these sustainability packages could be based on an amended version of the current Sustainable Engineering package. Three main levels of activity are shown: the SMS programme provides university-wide CPD events, optional SD modules \& literary / skills workshops and SD industry-based interdisciplinary group projects; Individual Faculty packages offer faculty-specific CPD events, optional modules and group projects; and finally Discipline-specific courses, modules \& individual projects / dissertations. 

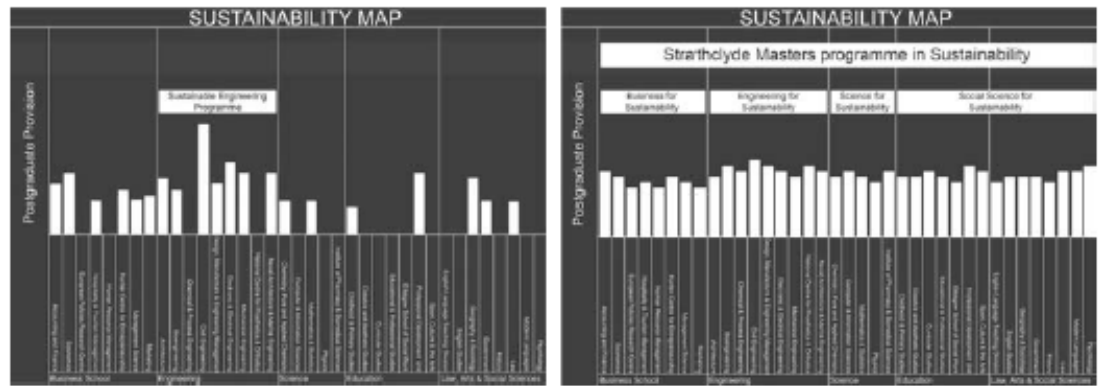

Figure 4: (a) Current Sustainability Maps \& (b) Future Sustainability Map

Table 3: Example of Masters Courses and Modules Aligned by Departments within the Faculty of Law, Arts and Social Sciences

\begin{tabular}{|l|l|}
\hline \multicolumn{2}{|l|}{ Department of Economics - Modules } \\
\hline $\begin{array}{l}\text { Environmental Modelling } \\
\text { Environmental Economics }\end{array}$ & $\begin{array}{l}\text { International Environmental Policy } \\
\text { Pollution Control Policy }\end{array}$ \\
\hline Hunter Centre for Entrepreneurship - Modules \\
\hline $\begin{array}{l}\text { Accessing Resources } \\
\text { Entrepreneurship: Personal } \\
\text { Effectiveness } \\
\text { Finance and the Growing Business }\end{array}$ & $\begin{array}{l}\text { Opportunity Recognition } \\
\text { Dechnology Venture Management }\end{array}$ \\
\hline Department of Management Science - Modules \\
\hline Research Methods and Participatory Processes \\
\hline Department of Marketing - Masters Courses \\
\hline MSc Marketing & MSc International Marketing \\
\hline Department of Marketing - Modules \\
\hline $\begin{array}{l}\text { Globalisation and Corporate Social } \\
\text { Responsibility }\end{array}$
\end{tabular}

A draft structure for the SMS programme has also been developed as a version of the successful model which has been running within the Sustainable Engineering since 1999 (Table 4). In this expanded version the aim is to enhance teaching quality and the students' learning experience through an integrated and co-ordinated programme that operates efficiently across the University, implementing Strathclyde's Vision by drawing on discipline strengths within Faculties to provide an interdisciplinary response to the major challenges presented within the Sustainable Development agenda. The challenges are both global and local in nature. Strathclyde's profile as a research-led institution consolidating a reputation for innovation in learning and teaching, building upon a long tradition of strong engagement with government, business, industry and local communities, positions the University well to meet this 
challenge. The University's aspirations build upon the history of a "place of useful learning" that is both locally grounded and internationally minded.

Table 4: Draft SMS Programme and Teaching Structure

\begin{tabular}{|l|l|}
\hline \multicolumn{3}{|c|}{ (SMS) PROGRAMME STRUCTURE } \\
\hline Step One: Select Faculty Package \\
\hline - $\quad$ BUSINESS FOR SUSTAINABILITY \\
- $\quad$ HUMANEERING FOR SUSTAINABILITY \\
- SCIENCE FOR SUSTAINABILITY
\end{tabular}

\section{Conclusion}

As an emerging leader in the field of ESD, the University of Strathclyde plans to develop a framework to implement a new Strathclyde Masters programme in Sustainability (SMS) which aims to promote and undertake a visionary programme of pan-University, cross-disciplinary research and postgraduate teaching in sustainable development. The SMS Project Management Team has examined the processes involved in developing such a framework and a number of conclusions have been drawn from each stage; the review of current thinking in ESD, the multi-stakeholder consultation process and the creation of a Sustainability Map of the University.

The definition and priorities of SD are complex and multi-layered and the challenges of $\mathrm{SD}$, being inherently holistic, require responses from all disciplines and professions represented within the institution. However, the Sustainability Map has shown that the current level of provision of postgraduate ESD varies greatly across the University. This requires 
the development of a framework for pan-University, cross disciplinary teaching and the existing Masters Programme in Sustainable Engineering offers a model on which such a framework might be based.

The need for knowledge and understanding of the complex issues involved in SD is coupled with the need for practical skills. There is a demand from students and external collaborators for sustainability and its associated interdisciplinary skills to be given more emphasis with the University. This is currently being addressed by the University's Education Strategy Committee. It will be necessary for Faculties to commit resources in order to progress the development of the SMS. Outcomes from the initial research process, as presented in this paper, will be used to inform continued consultation with all stakeholders which will focus on developing the structure and academic content of the programme.

\section{References}

Centre for Sustainable Futures Occasional Paper 3, Getting it Together: Interdisciplinarity and Sustainability in the Higher Education Institution, (CSF, 2009).

Engineering Education for Sustainable Development, European sustainability rankings, Observatory Report, 2008 (EESD, 2008) Available online: https://www.upc.edu/eesdobservatory/why/reports/EESD_Observer_2008_.pdf

Higher Education Academy (HEA), Sustainable Development in Higher Education, Current Practice and Future Developments - A Progress Report for Senior Managers in Higher Education (HEA, Jan 2006)

Higher Education Academy (HEA), Engineering Subject Centre Mini-Project Report, Engineering Education for Sustainable Development - Report of a Delphi Consultation, ISBN 97-8190480-4727 (HEA, Apr 2008)

Higher Education Academy (HEA), Dr Alex Ryan, 2008 Review of Education for Sustainable Development (ESD) in Higher Education in Scotland - Final Report (HEA, Feb 2009)

The United Nations, World Summit on Sustainable Development in Johannesburg, South Africa, declared: United Nations Decade of Education for Sustainable Development (UNDESD, Johannesburg Summit, 2002)

United Nations Development Programme. (2007). The Human Development concept. Available: http://hdr.undp.org/en/humandev/. Last accessed 01 June 2010. (UNDP, 2007)

UNESCO, Guidelines and Recommendations for Reorienting Teacher Education to Address Sustainability (UNESCO 2005)

UNESCO, Review of Contexts and Structures for Education for Sustainable Development 2009 (UNESCO 2009)

UNESCO, Quality Education, Equity and Sustainable Development (UNESCO, Nov 2008)

United Nations World Commission on Environment and Development, Our Common Future, The Brundtland Report (UNWCED, 1987) 


\section{About the Authors}

Dr. David Grierson

Dr. Grierson is both an architect and academic. He is currently Director of Postgraduate Research in Architecture and has directed the Postgraduate Programme in Sustainable Engineering at University of Strathclyde Glasgow since 2004. His teaching and research interests are in sustainable architecture and urban design. He is particularly active in the integration of teaching and learning activity across the postgraduate community, and the promotion of knowledge exchange through increased engagement with business, industry, the professions, and other institutions. Dr. Grierson is a Fellow of the Higher Education Academy (FHEA) and a visiting professor at Universities in Rome and Florence. His own architectural work has been exhibited at the Royal Academy Exhibition in London and he has gained a number of architectural awards including two Glasgow Institute of Architecture (GIA) Design Awards. $\mathrm{He}$ is a recipient of the Sir Rowan Anderson Silver Medal for Architectural Design from th Royal Institute of Architects in Scotland (RIAS).

\section{Claire Hyland}

Claire Hyland graduated from Postgraduate Studies at the University of Strathclyde, Glasgow in 2007. She is currently employed as a Sustainability Research Assistant in the Department of Architecture at Strathclyde supporting Dr. David Grierson in consulting widely on the framework for developing new postgraduate activity in the area of environmental, social, and economic sustainability. Claire's main interests are in sustainable and accessible architecture and urban design, education and graphic design. She is also currently working with a visually impaired $\mathrm{PhD}$ student of Architecture, assisting in his research and image production and gaining experience through tutoring students. Additional projects include working in collaboration with colleagues in creating and designing workshop activities for school children based on sustainable communities (event to be held in the Science Centre, Glasgow as part of the ESRC Festival of Social Science 2010). Previous to her engagement at the university, Claire gained professional experience working in architectural practices both in the Glasgow and Spain, where she experienced a different culture and working methods as well as gaining fluency in the language. 